\title{
Inclusión financiera: Factor clave en la esperanza de vida de las Mipymes en países de Latinoamérica
}

\section{Financial inclusion: Key factor in the life expectancy of MSMEs in Latin American countries}

JIMÉNEZ-RICO, Artemio †*, LAGUNA-CÓRDOBA, Perla Cristina y GUTIÉRREZ-RANGEL, Héctor Fabián

Universidad de Guanajuato, División de Ciencias Económico-Administrativas, Guanajuato, Guanajuato, México

ID $1^{\text {er }}$ Autor: Artemio, Jiménez-Rico / ORC ID: 0000-0001-9069-6483, Researcher ID Thomson: S-7880-2018, CVU CONACYT ID: 947479

ID $1^{\text {er }}$ Coautor: Perla Cristina, Laguna-Córdoba / ORC ID: 0000-0002-6675-1259, Researcher ID Thomson: S-6908-2018, CVU CONACYT ID: 947248

ID $2^{\text {do }}$ Coautor: Héctor Fabián, Gutiérrez-Rangel / ORC ID: 0000-0001-6970-723X, Researcher ID Thomson: S-85142018, CVU CONACYT ID: 745113

DOI: $10.35429 / J E D .2019 .20 .6 .6 .17$ Recibido: 10 de Junio, 2019; Aceptado 30 de Septiembre, 2019

\section{Resumen}

Las Mipymes son de vital importancia en el desarrollo económico y social de las naciones de América Latina, comprenden el $99 \%$ de las empresas formales latinoamericanas, son las principales generadoras de empleo con el $61 \%$ y contribuyen con el $25 \%$ del PIB de dicha región. Desafortunadamente, el promedio de su esperanza de vida es menor a 10 años porque dichos negocios enfrentan diversos problemas, destacando el acceso al financiamiento. El objetivo de esta investigación es determinar el impacto de la inclusión financiera en la esperanza de vida de las Mipymes de México, Colombia, y Chile. Se realiza un exhaustivo análisis de ambas variables con datos de informes, encuestas y estudios especializados. Algunos resultados indican que la principal fuente de financiamiento de estas empresas no son las instituciones financieras, por el contrario, son los recursos que invierten sus propietarios y el principal obstáculo para no acceder al financiamiento externo son las altas tasas de interés. Esta investigación contribuye en mostrar las condiciones actuales de las Mipymes con la finalidad de que se diseñen políticas públicas que fortalezcan la inclusión financiera para mejorar su permanencia y competitividad en el mercado.

Inclusión financiera, Esperanza de vida, Mipymes.

\begin{abstract}
MSMEs are of vital importance in the economic and social development of the nations of Latin America, comprise 99\% of the formal Latin American companies, are the main generators of employment with $61 \%$ and contribute with $25 \%$ of the GDP of that region. Unfortunately, the average life expectancy is less than 10 years because these businesses face various problems, highlighting access to financing. The objective of this research is to determine the impact of financial inclusion on the life expectancy of MSMEs in Mexico, Colombia and Chile. An exhaustive analysis of both variables is carried out with data from reports, surveys and specialized studies. Some results indicate that the main source of financing for these companies is not the financial institutions, on the contrary, they are the resources that their owners invest and the main obstacle to not accessing external financing is the high interest rates. This research contributes to show the current conditions of MSMEs in order to design public policies that strengthen financial inclusion to improve their permanence and competitiveness in the market.
\end{abstract}

Financial inclusion, Life expectancy, MSMEs

Citación: JIMÉNEZ-RICO, Artemio, LAGUNA-CÓRDOBA, Perla Cristina y GUTIÉRREZ-RANGEL, Héctor Fabián. Inclusión financiera: Factor clave en la esperanza de vida de las Mipymes en países de Latinoamérica. Revista de Desarrollo Económico. 2019. 6-20: 6-17

\footnotetext{
* Correspondencia del Autor (correo electrónico: a.jimenezrico@ugto.mx)

$\dagger$ Investigador contribuyendo como primer autor.
} 


\section{Introducción}

El fenómeno de las Mipymes en la actualidad, a nivel latinoamericano y mundial, atrae en forma fascinante la atención de los sectores educativo, público, empresarial y profesional, pues hoy por hoy, es reconocido como la alternativa real para el desarrollo económico de las naciones (Chirino, 2007).

$\mathrm{Su}$ importancia radica en que las Mipymes abarcan el 99\% de las empresas formales de América Latina, generan el 61\% del empleo y aportan el 25\% del Producto Interno Bruto (PIB) de esta zona, por tal motivo, representan un factor clave en el crecimiento económico y social de los países (Dini y Stumpo, 2018).

Desafortunadamente, estos negocios enfrentan diversos problemas, entre los que destaca el acceso a financiamiento, situación que dificulta su crecimiento y competitividad, llevándolas incluso a su desaparición, por lo que su esperanza de vida promedio no alcanza ni los 10 años. Asimismo, las políticas y programas públicos encaminados a mejorar la competitividad y desarrollo de las Mipymes son pocos, aislados y no han tenido éxito.

Ahora bien, la inclusión financiera a Mipymes consta del acceso a productos financieros útiles y asequibles para satisfacer necesidades empresariales de manera responsable y sostenible.

El estudio de la inclusión financiera es un tema relevante en la economía de cada país, a través de ésta los sectores sociales y empresariales tienen mayor posibilidad de acceder a los productos y servicios financieros, con el fin de lograr un mayor crecimiento económico, mejorar la competitividad empresarial, así como brindar estabilidad financiera a sus usuarios.

Uno de los principales factores por los cuales las microempresas pierden competitividad en un entorno globalizado es la falta de acceso a créditos por parte de instituciones financieras y gubernamentales. Además, la escasa educación financiera ha conllevado al desconocimiento y falta de interés por profesionalizar sus negocios, situación que implica la desaparición de estos negocios en un horizonte corto de vida.
En esta sintonía, al no acceder a recursos financieros de instituciones de banca múltiple, las posibilidades de mejorar su nivel de competitividad se ven drásticamente disminuidas, situación que las deja en un estado de vulnerabilidad ante las grandes cadenas comerciales, y por ende tengan una alta tasa de mortandad.

Por lo antes expuesto, el objetivo de esta investigación es determinar la relación entre la inclusión financiera y la esperanza de vida de las Mipymes de México y países emergentes de América Latina. Para efectos de este estudio sólo se seleccionaron Colombia y Chile porque presentan situaciones económicas similares al de México. En este sentido, se contrastó el número de Mipymes existentes con aquellas poseedoras de financiamiento, el crédito otorgado para operaciones empresariales, así como el acceso a los servicios financieros para determinar la aplicación de la inclusión financiera. Además, se analizaron las diferencias en la esperanza de vida de estos negocios de los países objeto de estudio. Este estudio contribuye a mostrar a los diversos agentes económicos y gobiernos la importancia que tiene la inclusión financiera para mejorar la competitividad de las Mipymes e incrementar su permanencia en el mercado.

\section{Revisión de la literatura}

\section{Importancia de las Mipymes}

A nivel internacional, las Mipymes representan un gran segmento del sector privado, siendo una importante fuente de trabajo para familias de escasos recursos, por lo que contribuyen al desarrollo de los países, a la reducción de la pobreza, mayor productividad e innovación, así como también a la igualdad y equidad social (Ortiz, 2019). En este sentido, el 99.5\% de las empresas latinoamericanas son Mipymes, generan el $61 \%$ del empleo formal y se han convertido en importantes proveedores de bienes y servicios para las medianas y grandes empresas (Gallo, 2019). Asimismo, entre los países de América Latina, las Mipymes en conjunto generan más del $60 \%$ del empleo formal y representan un 25\% del PIB de esta región, comparado con las de la Unión Europea donde esta cifra alcanza el 56\%, podemos darnos cuenta de que, dichas empresas pueden mejorar su desempeño para brindar un mayor desarrollo, pero primordialmente deben ser capaces de superar las dificultades financieras (Dini y Stumpo, 2018).

JIMÉNEZ-RICO, Artemio, LAGUNA-CÓRDOBA, Perla Cristina y GUTIÉRREZ-RANGEL, Héctor Fabián. Inclusión financiera: Factor clave en la esperanza de vida de las Mipymes en países de Latinoamérica. Revista de Desarrollo Económico. 2019 
En el caso de México, sucede algo similar, las Mipymes son un componente fundamental para el desarrollo económico del país, comprenden más del $99 \%$ del total de las unidades económicas, contribuyen a generar alrededor del 52\% del PIB y más del 70\% de los empleos formales (DOF, 2009). En contraste, a pesar de la importancia de la permanencia de las Mipymes para la economía mexicana, alrededor del $70 \%$ de los nuevos negocios no llegan al tercer año de vida (Klynveld Peat Marwick Goerdele [KPMG], 2016).

De la misma manera, la situación de las Mipymes de Colombia está en estrecha relación con las de América Latina, generan una extensa contratación de empleados y aportan casi el $40 \%$ del PIB nacional de Colombia, es por ello necesario replantear la gestión financiera de estas organizaciones con el fin aumentar su competitividad y preservar su permanencia (Correa, Ramirez, y Castaño, 2009). En la actualidad, a pesar de las grandes iniciativas de programas de promoción y de apoyo, promovidos desde los gobiernos y los organismos de cooperación, los resultados no reflejan las expectativas generadas (Árevalo y Sosa, 2015).

Por otra parte, las empresas de gran tamaño son escasas, la responsabilidad de mantener en marcha la economía recae sobre los hombros de las empresas de menor tamaño (KPMG, 2016). En este sentido, en las últimas décadas, las grandes empresas apenas crearon el $1 \%$ de los nuevos empleos, mientras que las Mipymes, fueron las generadoras de la mayoría de los nuevos puestos de trabajo (Ángeles, 2014).

Si bien en la mayoría de los países más de la mitad de los puestos de trabajo son generado por Mipymes, es claro también que los trabajos generados por Mipymes no son, en general, de la misma calidad que aquellos generados por las empresas más grandes: las Mipymes tienden a pagar salarios menores, a proliferar más en sectores de baja productividad $\mathrm{y}$, dadas las altas tasas de nacimiento $\mathrm{y}$ mortalidad de Mipymes, los puestos de trabajo en ellas tienden a ser menos estables (Rojas, 2015).
En este sentido, las Mipymes mexicanas tienen que superar varios obstáculos para su desarrollo, entre los principales están los siguientes: difícil acceso a financiamiento, poca información sobre mercados de sus productos, capital humano con poca capacitación, uso limitado de las TIC, entre otros. En contraste, los instrumentos para mejorar la competitividad son los que contribuyen a la vinculación, el financiamiento, la capacitación y la innovación en las Mipymes (Larios, 2016).

En la misma sintonía, Saavedra, Tapia y Aguilar (2013) mencionan algunas problemáticas de las Mipymes en México, entre los que destacan los siguientes: falta de capacitación y falta de conocimientos administrativos de su personal; falta de información sobre los instrumentos de apoyo a las Mipymes; altos costos de servicios públicos y de infraestructura; excesivo costo de créditos financieros; difícil acceso a la tecnología; y la inseguridad pública, entre otros.

El financiamiento actúa como un agente importante para las empresas, sin embargo, más de dos terceras partes de las Mipymes expresan que es complicado obtener créditos formales y es por ello que su principal fuente de financiamiento son los proveedores. (Nielsen Company y Visa, 2012).

Las Mipymes no cuentan con muchos recursos necesarios para su pleno desarrollo, la principal limitante es el acceso al financiamiento. Otra problemática que resalta son las bajas inversiones en desarrollo tecnológico, infraestructura y el limitado acceso a mercados de exportación (Martinez, 2015).

De igual manera, Molina, López \& Schimtt (2016) indican que, si se analiza las Mipymes con base en sus funciones administrativas, apoyos financieros y técnicos, así como a su estructura legal y operativa, resalta que la planeación de las Mipymes está centrada en el dueño de la empresa, es operativa más que estratégica, por lo que tiene un horizonte de corto plazo y se basa en la experiencia más que en el análisis. Por lo tanto, podemos resaltar que las empresas se preocupan por el día a día de sus operaciones y no en su crecimiento y desarrollo. 
Además, las Mipymes en toda América Latina enfrentan dificultades asociadas a su tamaño, como el acceso restringido a fuentes de financiamiento, bajos niveles de capacitación de sus recursos humanos, limitados niveles de innovación y desarrollo tecnológico, baja penetración en mercados internacionales, bajos niveles de productividad y baja capacidad de asociación administrativa (Mejía, 2018).

\section{Inclusión financiera en las MIYMES}

La inclusión financiera se define en términos de tres dimensiones: 1.- Acceso: todas las instituciones financieras que posibilitan el acceso a estos servicios. 2.-Uso: se refiere a las necesidades a las que ira dirigida tal servicio otorgado. 3.- Calidad: es vinculada a la eficiencia otorgada por parte de las instituciones financieras al otorgar el servicio y el uso para satisfacer las necesidades del beneficiario (Ferraz y Ramos, 2018).

Por otra parte, el Banco Mundial (2018) señala que la inclusión financiera se refiere a productos financieros útiles y accesibles que satisfagan las necesidades de las empresas como: transacciones, pagos, ahorros, crédito y seguro, los cuales son prestados de manera responsable y sostenible para su beneficio.

En este sentido, la banca es un actor clave en la economía de un país porque ejerce un control en las finanzas; a nivel macro, por medio de la promulgación de las políticas económicas de una nación y, a nivel micro, contribuyendo al desarrollo de la economía desde varios frentes (Azofeifa, 2019)

Los servicios financieros facilitan la vida de la empresas ya que les permite establecerse, desde un objetivo a largo plazo hasta las emergencias imprevistas. Además, pueden obtener créditos para iniciar un negocio o ampliarlo, invertir y sortear crisis financieras, con el fin de mejorar la esperanza de vida de sus negocios (Banco Mundial, 2018).

Asimismo, las microempresas que tienen acceso a crédito formal tienen más recursos disponibles para capital de trabajo, inversión para compra, ampliación o remodelación del local, y para cubrir gastos normales del negocio (Mejía, 2018).
Por el contrario, la falta de financiamiento es una de las grandes barreras que dificultan el desempeño de las Mipymes, debido a que al enfrentarse a estos problemas buscan alternativas no reguladas para obtención de financiamiento aceptando altos costos y riesgo inherentes a estos tipos de créditos. (Ortiz \& Vizueta, 2019)

De igual manera, las Mipymes que carecen de servicios y productos financieros acorde a sus necesidades, dificultan su crecimiento y competitividad, ocasionando un impacto negativo para las empresas. Por tal razón, las empresas enfrentan muchos desafíos en materia de financiamiento, lo que contribuye a una alta mortalidad empresarial (Pérez y Titelman, 2018).

En el mismo sentido, los servicios financieros para las empresas de América Latina han crecido en los últimos años y cuentan con una amplia cobertura potencial ayudándolos a mejorar su esperanza de vida. Los índices de bancarización son altos en Chile y Colombia, dejando a México por debajo de la media de Latinoamérica (Lecuona y Pavón, 2018). En Colombia se han implementado medidas para incrementar el financiamiento a las Mipymes, se creó un importante entramado de instituciones y programas públicos destinados a promover la inclusión financiera y el financiamiento a estas empresas (Kulfas, 2018).

Además, Colombia y Perú ocuparon los dos primeros lugares en la clasificación general de inclusión financiera del microscopio global 2018. También, lideran el índice de políticas públicas y apoyo de sus gobiernos para la inclusión financiera (Gallo, 2019)

Respecto al financiamiento de las Mipymes en Latinoamérica, Saavedra y León (2014) indican:

- Los fondos internos y utilidades retenidas son la fuente de financiamiento de las Mipymes para capital de trabajo más utilizada en donde el $62.15 \%$ corresponde a México, el $55.27 \%$ en Chile y Colombia con el menor porcentaje del $37.57 \%$.

Los préstamos bancarios en Colombia alcanzan el $20.53 \%$, en Chile $18.11 \%$ y en México el $8.50 \%$. 
- Los préstamos de instituciones financieras no bancarias son la fuente de financiamiento de las Mipymes para capital de trabajo menos utilizada, Chile con $1.53 \%$, México con $1.30 \%$ y Colombia con $1.27 \%$.

- Las compras a crédito de proveedores y adelantos de clientes es la segunda fuente de financiación de las Mipymes, en Colombia con el $36.01 \%$, México con el $24.68 \%$ y Chile con el $23.32 \%$.

Otros (prestamistas, amigos, parientes, etc.) recurren países como Colombia con el $4.63 \%$, México con $3.37 \%$ y Chile con $1.77 \%$.

En la misma sintonía, Vite \& García (2015) identificaron que la principal fuente de financiamiento de las Mipymes de Latinoamérica no son las instituciones financieras sino los recursos que invierten sus propietarios y el principal obstáculo para no acceder al financiamiento externo son las altas tasas de interés.

\section{Esperanza de vida de las Mipymes}

La esperanza de vida o la permanencia de las Mipymes en el mercado se puede medir mediante un enfoque retrospectivo de seguimiento generacional, es decir un procedimiento prospectivo de una o más generaciones a través de encuestas continuas longitudinales, en intervalos de tiempo futuros y equidistantes (INEGI, 2014).

Por otra parte, Molina et al. (2016) infirieron que la estructura administrativa económica de la Mipymes está relacionada con su tasa de mortandad, por medio del financiamiento. Esto se debe a que no considera relevantes las actividades de planeación, administración y toma de decisiones financieras, puesto que no genera información financiera que refleja la situación real de la empresa, no utiliza la planeación para tomar decisiones sobre las inversiones o para establecer la combinación ideal de financiamiento a corto y largo plazo.

Naranjo (2013) expone que existen numerosos factores por los cuales un negocio puede llegar al fin de su ciclo de vida, diversos autores lo atribuyen a su carente cultura empresarial y estancamiento en el desarrollo y crecimiento de la organización.
Claro está que al competir con grandes empresas que cuentan con acceso a financiamiento y diversos productos financieros tanto para su uso y el de sus clientes, marca una gran brecha competitiva desfavorable para las Mipymes. De la misma manera, la relación del acceso al crédito se ha identificado como una restricción que influye en la toma de decisiones de una Mipymes, tanto para invertir en actividades de innovación y desarrollo empresarial, fundamentalmente el acceso a conocimiento, capital humano y financiamiento. Lo anterior se vincula a diversas fallas del acceso al crédito como la falta de garantías, altos costos de transacción, insuficiente desarrollo de instrumentos financieros alternativos, problemas en la oferta crediticia de intermediarios financieros, etc. (Castillo, Figal, Maffioli, y Ohaco, 2016).

Bermudez \& Bravo (2019) en su estudio sobre las determinantes de probabilidad del cierre empresarial de las Mipymes, identificaron que incrementar el apalancamiento financiero, disminuir las cuentas por cobrar, invertir en activo fijo neto y mantener niveles altos de rentabilidad son algunos de los factores que aumentan la esperanza de vida de las empresas. Asimismo, señalan que un endeudamiento responsable puede permitir mejorar la competitividad empresarial e incrementar su horizonte de vida.

Para el caso de Chile, destaca la importancia de las microempresas en el total de muertes que se observa cada año, donde en promedio para el periodo 2006-2013, un $68.7 \%$ de las empresas que mueren son micro. Sin embargo, se observa una continua disminución en la participación de microempresas que muere cada año, pasando del $70.2 \%$ de las empresas que murieron el 2005 al $65.7 \%$ el 2013 (Arellano y Jiménez, 2016). Por otra parte, para Colombia, Global Entrepreneurship Monitor (citado en Mora, Vera y Melgarejo, 2015) expone que los problemas organizacionales de las Mipymes del país les restan competitividad en el mercado y genera que un alto porcentaje de estas (50-75\%) desaparezca en los 3 primeros años. En México, solo el $10 \%$ de la MYPES maduran, crecen y tienen éxito al cumplir los 10 años de existencia. Otros datos muestran que $75 \%$ de las nuevas empresas mueren después de dos años en el mercado; $50 \%$ de los mismos quiebran durante el primer año de actividad, y no menos $90 \%$ antes de cinco años. 
En Chile, en un estudio en el que se les dio seguimiento a 67,310 negocios creados a partir de 1996, se encontró que $25 \%$ de estos desaparecieron en el primer año, $17 \%$ en el segundo, $13 \%$ en el tercero y $11 \%$ en el cuarto año (Moreno, Cuevas y Michi, 2015).

\section{Metodología a desarrollar}

La metodología utilizada en esta investigación es documental, en virtud de que los datos se obtuvieron a través de la revisión de diversas páginas oficiales de instituciones como el Banco Mundial, el Instituto Nacional de Estadística y Geografía (INEGI), la Comisión Económica para América Latina y el Caribe (CEPAL), la Comisión Nacional para la Protección y Defensa de los Usuarios de Servicios Financieros (CONDUSEF), entre otras, así como de encuestas nacionales e internacionales sobre las temáticas de Mipymes y de la participación de estas en las economías nacionales y regional, como por ejemplo la Encuesta Nacional sobre Productividad y Competitividad de las Micro, Pequeñas y Medianas Empresas (ENAPROCE), la Encuesta Longitudinal de Empresas en Chile, la Encuesta de Opinión Empresarial de la CEPAL, entre otras.

Posteriormente se procedió a la construcción del concentrado de datos y elaboración de gráficas con el propósito de observar el comportamiento de las variables en cuestión. Finalmente, una vez recabados los datos, el análisis consistió en contrastar la información con la finalidad de buscar mayor objetividad en relación con el objetivo y las premisas planteadas en esta investigación.

\section{Resultados}

\section{Importancia de las Mipymes}

El número de empresas en cada país varía. México contaba en 2014 con 4,048,543 Mipymes, de las cuales 3,952,422 son micro, 79,367 pequeñas y 16,754 medianas (INEGI, 2016); Colombia contaba con un total de 2,540,953, de las cuales 2,272,200 son micro, 114,914 pequeñas, 29,107 medianas y 124,729 no determinadas debido a que sus datos no han sido actualizados (Confecámaras, 2016); y Chile con un total de 887,253 , de las cuales 673,026 son micro, 186,190 pequeñas y 28,037 medianas (Servicio de Impuestos Internos, 2015).
Ahora bien, al analizar las Mipymes en proporción respecto del total de empresas en los países objeto de estudio, observamos que las que tienen una evidente participación son las microempresas, dejando a las grandes empresas con los porcentajes más bajos, ver tabla 1 .

\begin{tabular}{|c|c|c|c|c|} 
Pais & Micro & Pequeĩas & Medianas & Grandes \\
\hline México & $95,5 \%$ & $3,6 \%$ & $0,7 \%$ & $0,2 \%$ \\
\hline Colombia & $96,4 \%$ & $3,0 \%$ & $0,5 \%$ & $0,1 \%$ \\
\hline Chile & $78,3 \%$ & $17,6 \%$ & $2,7 \%$ & $1,4 \%$ \\
\hline
\end{tabular}

Tabla 1 Proporción de empresas según tamaño Fuente: Stumpo (2013)

Como se observa en la tabla 2, el sector de actividad con mayor participación entre Mipymes de América Latina es el comercio al por mayor y menor con un total del $41 \%$ en participación considerando a todas las empresas, destacando las microempresas en el primer lugar de intervención en dicha área con un $42 \%$.

\begin{tabular}{lccccc}
\hline Sector & Microempresa & Pequeña & Mediana & Grande & Total \\
\hline Agricultura, ganaderia, caza, silvicultura y pesca & 2 & 4 & 5 & 4 & 3 \\
Explotación de minas y canteras & 0 & 0 & 1 & 1 & 0 \\
Industria manufacturera & 9 & 14 & 19 & 22 & 10 \\
Suministro de electricidad, gas y agua & 0 & 0 & 1 & 2 & 0 \\
Construcción & 3 & 7 & 9 & 7 & 3 \\
Comercio al por mayor y menor & 42 & 31 & 23 & 21 & 41 \\
Hoteles y restaurantes & 8 & 8 & 4 & 2 & 8 \\
Transporte, almacenamiento y comunicaciones & 5 & 7 & 8 & 8 & 5 \\
Intermediación financiera & 1 & 2 & 3 & 6 & 1 \\
Actividades inmobiliarias, empresariales y de alquiler & 12 & 13 & 13 & 12 & 12 \\
Enseñanza & 2 & 4 & 6 & 6 & 2 \\
Servicios sociales y de salud & 4 & 4 & 4 & 4 & 4 \\
Otras actividades comunitarias, sociales y personales & 11 & 4 & 4 & 4 & 10 \\
Total & 100 & 100 & 100 & 100 & 100 \\
\hline
\end{tabular}

Tabla 2 Cantidad de empresas según tamaño y sector de actividad en América Latina, 2016 (en porcentaje)

Fuente: Dini y Stumpo (2018)

En la tabla 3 se muestra que las microempresas en Colombia son las que tienen mayor participación del personal ocupado, generan el $50.6 \%$ de empleos, comparado con México $45.6 \%$, y Chile $44.1 \%$. Por esta razón, las Mipymes representan la principal fuente de empleo en todos los países.

\begin{tabular}{|c|c|c|c|c|}
\hline País & Micro & Pequeñas & Medianas & Grandes \\
\hline México & $45,6 \%$ & $13,3 \%$ & $10,3 \%$ & $30,8 \%$ \\
\hline Colombia & $50,6 \%$ & $17,5 \%$ & $12,8 \%$ & $19,1 \%$ \\
\hline Chile & $44,1 \%$ & $17,7 \%$ & $13,2 \%$ & $25,0 \%$ \\
\hline
\end{tabular}

Tabla 3 Empleo según tamaño de las empresas Fuente: Stumpo (2013) 
En el caso de México, en la figura 1 se observa que el sector comercial es el más común entre las Mipymes con el 56.5\% de los negocios y contribuye con el $48.2 \%$ del personal ocupado; y en último lugar, están las manufactureras con el $11.1 \%$ de estas unidades económicas y generan el $18.9 \%$ de empleos formales (INEGI, 2016).

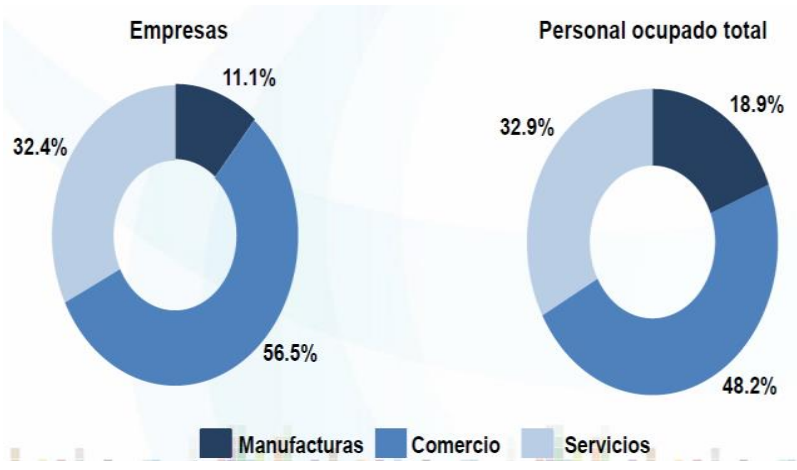

Figura 1 Distribución de empresas y personal ocupado por sector de actividad económica

Fuente: ENAPROCE, 2015, INEGI (2016

Las Mipymes son grandes aportadoras y participantes en el PIB de los países, son las principales agentes en la activación de la economía. Para México este grupo de empresas generan un 52\% del PIB (CONDUSEF, 2015), para Colombia solamente el 28\% (DANE, 2016) y para Chile el 60\% (Monsalves, 2014).

\section{Inclusión Financiera en las Mipymes}

En primer lugar, en México se analizó mediante la ENAPROCE 2015, cuáles fueron los principales problemas que consideran las Mipymes como causa por la cual no crece su negocio, para los fines de esta investigación se destaca la falta de crédito, siendo las micro empresas las que la señalan como su problemática más importante con un $22.7 \%$, en contraste, las pequeñas y medianas sólo la indican un $9.2 \%$ y un $6 \%$ respectivamente, ver detalle en la figura 2.

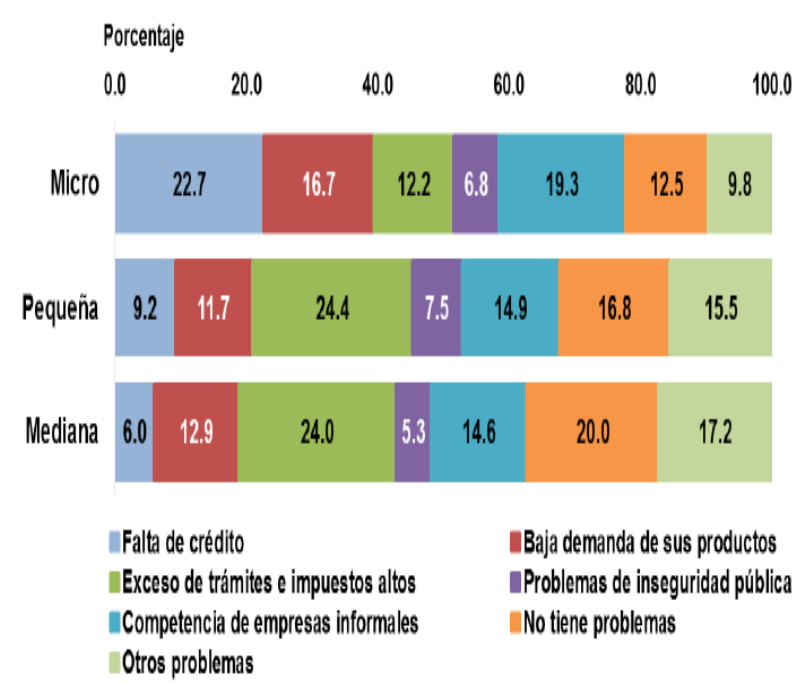

Figura 2 Distribución de empresas según la causa principal por la que consideran que sus negocios no crecen Fuente: ENAPROCE 2015, INEGI (2016)

En México existen tasas de interés altas para las Mipymes (12.5\% promedio ponderado), en cuanto más pequeña es la empresa su interés es mayor, por lo que las microempresas tienen una tasa promedio ponderado de $14.5 \%$, las pequeñas $12.2 \%$ y las medianas $10.8 \%$. Esta situación, afecta significativamente porque la mayoría de las empresas que más necesitan de dichos servicios para su supervivencia son las micro y pequeñas en comparación con las grandes empresas. Esto es debido a que el riesgo en los pequeños negocios es superior a los de mayor tamaño (Valdés, 2014), ver detalle en tabla 4.

\begin{tabular}{|c|c|c|c|c|c|c|}
\hline \multirow{2}{*}{$\begin{array}{c}\text { Tamaño de } \\
\text { empresa }\end{array}$} & \multicolumn{2}{|c|}{$\begin{array}{l}\text { Número de } \\
\text { créditos }\end{array}$} & \multicolumn{2}{|c|}{$\begin{array}{c}\text { Número de } \\
\text { empresas }\end{array}$} & Saldo & \multirow{2}{*}{$\begin{array}{c}\text { Tasa } \\
\text { promedio } \\
\text { ponderado } \\
\text { Por ciento }\end{array}$} \\
\hline & Total & $\begin{array}{c}\text { Por } \\
\text { ciento } \\
\end{array}$ & Total & $\begin{array}{c}\text { Por } \\
\text { ciento } \\
\end{array}$ & $\begin{array}{c}\text { Millones de Por } \\
\text { pesos ciento }\end{array}$ & \\
\hline Grande & 288,660 & 28.1 & 7,860 & 1.9 & $1,455,445.0 \quad 74.6$ & 7.9 \\
\hline PYME & 738,667 & 71.9 & 400,695 & 98.1 & $494,341.5 \quad 25.4$ & 12.7 \\
\hline Mediana & 30,787 & 3.0 & 4,015 & 1.0 & $71,098.8 \quad 3.6$ & 10.8 \\
\hline Pequeña & 331,046 & 32.2 & 143,382 & 35.1 & $284,610.1 \quad 14.6$ & 12.2 \\
\hline Micro & 376,834 & 36.7 & 253,298 & 62.0 & $138,632.6 \quad 7.1$ & 14.5 \\
\hline Total & $1,027,327$ & 100.0 & 408,555 & 100.0 & $1,949,786.5 \quad 100.0$ & 9.2 \\
\hline
\end{tabular}

Tabla 4 Cartera total de crédito al sector privado no financiero por tamaño de establecimiento Fuente: Banco de Mexico (2017)

En este sentido, en la figura 3 se observa que el principal motivo por el que las Mipymes no acpetarían un crédito bancario es porque consideran que son muy caros, situación que confirma que dichos negocios tienen que cubrir tasas de interés más altas que las de las grandes empresas. 


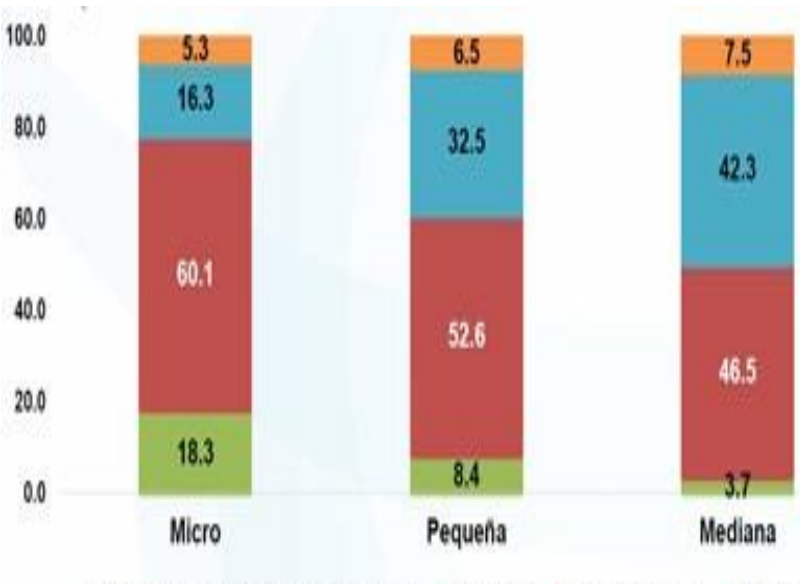

No tiene confianza en los bancos IEs caro NNo lo necesita Otras

Figura 3 Distribución del número de empresas según la razón por la cual no aceptarían un crédito bancario Fuente: ENAPROCE 2015, INEGI (2016).

En contraste, en la figura 4 se muestra que del 2010 al 2016, en Mexico ha crecido el financiamiento en las Mipymes, las pequeñas son el segmento más dinámico, al mostrar un crecimiento de $76 \%$ en cuanto al acceso al crédito, al pasar de 44 a 78 mil empresas; mientras que las microempresas con financiamiento pasaron de 209 mil a 262 mil, lo cual implica un crecimiento de $25 \%$. En su conjunto, las Mipymes con financiamiento crecieron en $33 \%$ al pasar de 258 a 344 mil empresas (Comisión Nacional Bancaria y de Valores, 2017).

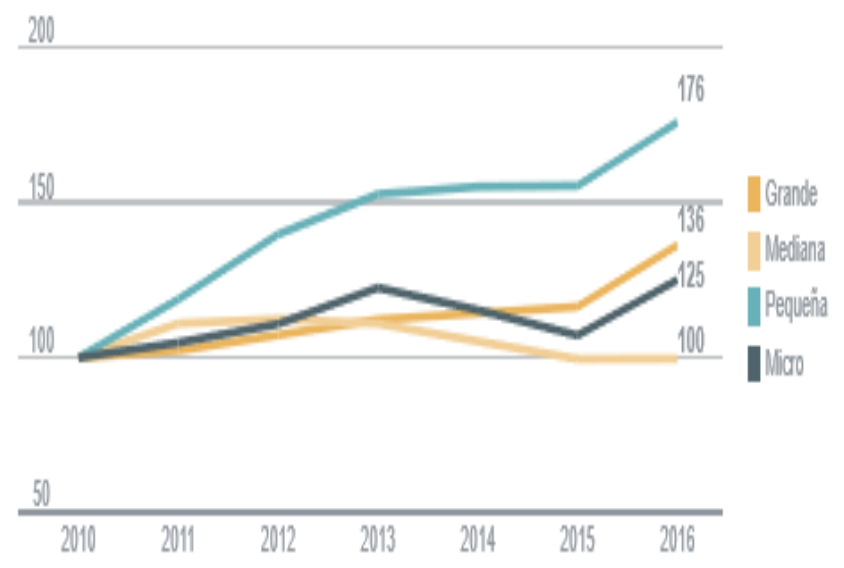

Figura 4 Índice de crecimiento del número de empresas con financiamiento

Fuente: Comisión Nacional Bancaria y de Valores (2017).

De igual manera en Colombia se puede observar que en los últimos años las Mipymes han disminuido sus solicitudes hacia créditos financieros siendo de 2015 a 2017 estas notables altibajos ya que menos de la mitad de las empresas encuestadas ha solicitado un crédito en los últimos años, cerrando en el 2018 con un total de 320,454 empresas con financiamiento.
Si bien México se presentan altibajos, se puede observar un mayor crecimiento en el acceso al financiamiento a partir del año 2013 a 2016 creciendo un $33 \%$ al pasar de 258 a 344 mil empresas, lo cual representa un mayor número de empresas financiadas en México en comparación a Colombia (ver figuras 3 y 5).

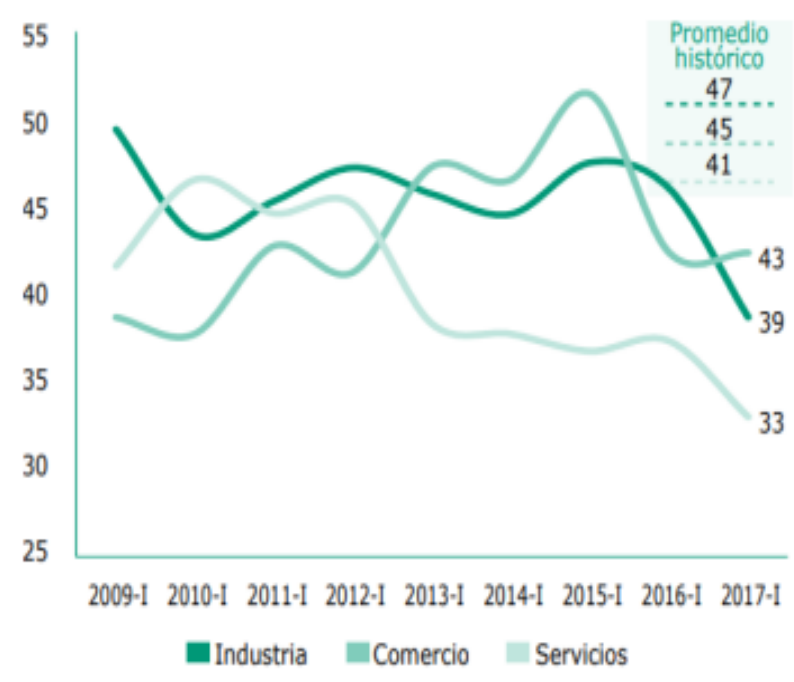

Figura 5 Acceso al crédito con el sistema financiero (\% de respuestas afirmativas).

Fuente: Álvarez, León, Arias y Londoño (2019).

Por otro lado, en Chile en el año de 2017 de una muestra de 339,022 empresas sólo el $19.66 \%(66,669)$ obtuvieron un financiamiento, cuando en México en el 2016 de un universo de 4.1 millones de Mipymes solo obtuvieron financiamiento el $8 \%(344,000)$, si bien Chile presenta un porcentaje de financiamiento más del doble que en México, en este se encuentra un mayor número de empresas con financiamiento, como se muestra en la figura 6 .

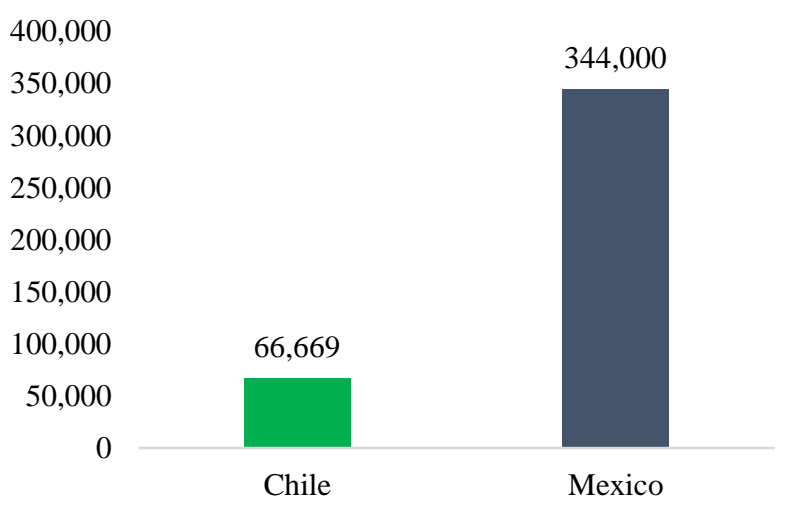

Figura 6 Número de Mipymes con financiamiento en Chile y México.

Fuente: Elaboración propia con datos del Ministerio de Economia, Fomento y Turismo (2019) y Comisión Nacional Bancaria y de Valores (2017) 
De igual manera en América Latina, según en la clasificación del nivel de desarrollo del mercado financiero, Chile tiene mayor disponibilidad de servicios financieros estando en el puesto $9 \mathrm{y}$ de acceso a estos servicios encontrándose en el puesto 15, en comparación a Colombia (69 y 99) y México (85 y 75), siendo el país más bajo de los analizados en esta investigación, ver tabla 5.

\begin{tabular}{|c|c|c|c|c|c|c|c|}
\hline & Argentina & Brasil & Chile & Colombia & Guatemala & México & Panamá Perú \\
\hline $\begin{array}{l}\text { Disponibilidad de los } \\
\text { servicios financieros }\end{array}$ & 130 & 98 & 8 & 69 & 22 & 85 & 1157 \\
\hline $\begin{array}{l}\text { Acceso a los servicios } \\
\text { financieros }\end{array}$ & 124 & 130 & 15 & 99 & 24 & 75 & 954 \\
\hline $\begin{array}{l}\text { Facilidad de acceso } \\
\text { a los préstamos }\end{array}$ & 116 & 87 & 16 & 61 & 29 & 78 & 48 \\
\hline Derechos legales & 106 & 106 & 85 & 1 & 12 & 8 & $30 \quad 22$ \\
\hline $\begin{array}{l}\text { Subindice de desarrollo } \\
\text { del mercado financiero }\end{array}$ & 121 & 92 & 17 & 27 & 18 & 36 & $14 \quad 35$ \\
\hline $\begin{array}{l}\text { Indice de } \\
\text { competifividad global }\end{array}$ & 92 & 80 & 33 & 66 & 84 & 31 & $50 \quad 72$ \\
\hline
\end{tabular}

Tabla 5 Acceso y uso de los Servicios Financieros Fuente: Pérez y Titelmann (2018)

\section{Esperanza de vida de las Mipymes}

Por desgracia en México, 65\% de las micro y pequeñas empresas mueren antes de cumplir 5 años y en promedio su esperanza de vida es tan sólo de 7.8 años (INEGI, 2014). Por otra parte, para Chile en los registros del Servicio de Impuestos Internos (SII) figuraban 988,745 empresas en 2012. De ese universo, el $64.4 \%$ poco más de 632 mil correspondía a microempresas, de las cuales 95 mil dejarían de existir al año siguiente. Las microempresas son en Chile el segmento más dinámico en cuanto a creación y muerte de empresas. El 15.2\% desaparece al primer año de vida; el mismo porcentaje dejará de existir al segundo año y luego, al tercero morirá otro 10.4\%. Sólo el $40 \%$ logra mantenerse al menos siete años (Arellano y Jimenez, 2016).

De modo idéntico la esperanza de vida de una nueva empresa en Colombia es de 5 años, siete de cada diez empresas mueren en sus primeros cinco años de funcionamiento; $50 \%$ quiebra tras el primer año y sólo el $20 \%$ llega al tercero (Confecámaras, 2016).
Ahora bien, en cada nación existen condiciones específicas que impactan en la tasa de mortandad de las Mipymes. Por ejemplo, en México la esperanza de vida de los negocios varía en cada estado del país desde 5.3 a 9.1 años, aun así, se establece un promedio nacional de 7.8 años al momento de nacer. Esto significa que la supervivencia de los negocios está estrechamente ligada con la zona geográfica y su giro, como se muestra en la figura 7 .

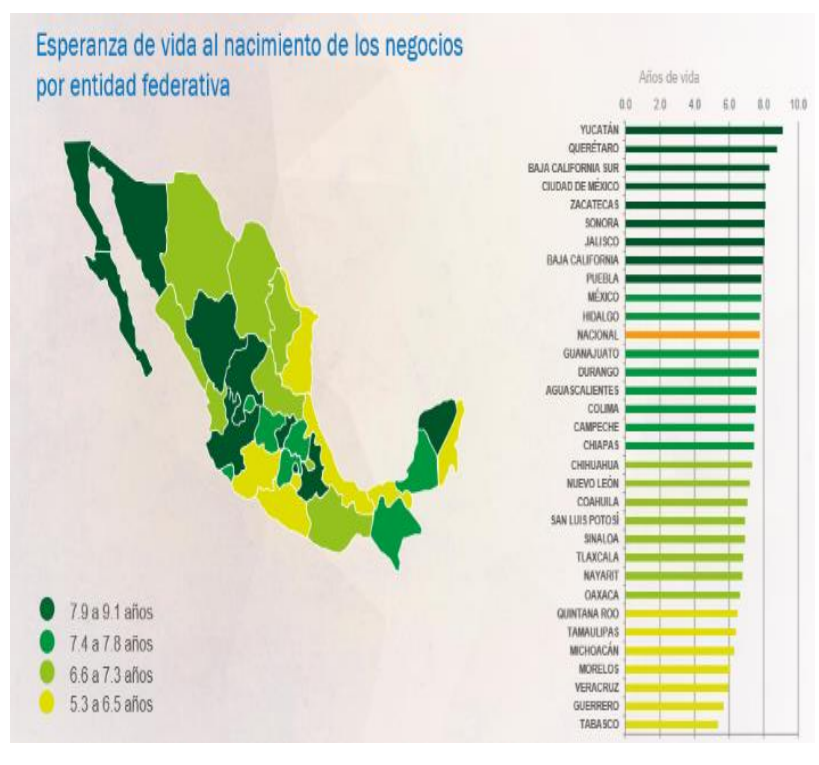

Figura 7 Esperanza de vida al nacimiento de los negocios en México

Fuente: INEGI (2016)

\section{Conclusiones}

La mayor parte de las empresas constituidas en un país son Mipymes, destacan las microempresas como las dominantes en número, por el contrario, las grandes empresas se ubican en el último lugar de cantidad según el tamaño de la firma. Además, México cuenta con más empresas que Colombia, y Chile.

El sector de actividad con mayor participación entre las Mipymes de América Latina es el comercio al por mayor y menor, destacando las microempresas con el primer lugar de intervención en dicha área. Asimismo, las microempresas son la principal fuente de empleo en México, Colombia y Chile, generan el $45.6 \%$, el $50.6 \%$ y el $44.1 \%$ del personal ocupado respectivamente (Stumpo, 2013). Además, las Mipymes son un factor clave en el motor de la economía, aportan desde un $28 \%$ a un $60 \%$ del PIB de estos países (CODUSEF, 2015; DANE, 2016; Monsalves, 2014; Olivera, 2014). 
Por otra parte, las Mipymes en México reciben financiamiento por parte del sector privado, sin embargo, les aplican tasas de interés más altas que a las grandes empresas. Según el Banco de México, la tasa de promedio ponderado en 2017 fue de $7.9 \%$ para las grandes empresas, 10.8 para medianas, 12.2 para las pequeñas y 14.5 a las micro (Banco de México, 2017).

En contraste, después del 2015 el número de Mipymes con financiamiento ascendió un $33 \%$ al pasar de 258 a 344 mil empresas (Banco de México, 2017). Por el contrario, en Colombia en los últimos años (2015 - 2017) las Mipymes redujeron sus solicitudes hacia créditos financieros con significativas disminuciones. Por otra parte, Chile apenas alcanza la cuarta parte de Mipymes con financiamiento que tiene México.

En este sentido, Vite \& García (2015) identificaron que la principal fuente de financiamiento de las Mipymes de América Latina no son las instituciones financieras, sino los recursos que invierten sus propietarios y el principal obstáculo para no acceder al financiamiento externo son las altas tasas de interés.

Las empresas que no forman parte de la inclusión financiera son más propensas a desarrollar un alto índice de mortandad. Desafortunadamente, este riesgo es mayor en las Mipymes que en las grandes empresas porque los recursos con que operan son limitados.

Se destaca que Chile y México son los países que más financiamiento han otorgado a las Mipymes, sin embargo, el promedio de vida de una nueva empresa en México es mayor que al de Chile y Colombia.

Derivado de la importancia de las Mipymes para el desarrollo económico de los países, es urgente que los actores involucrados diseñen programas y políticas públicas novedosas que impulsen la inclusión financiera para mejorar la competitividad de las Mipymes e incrementar su permanencia en el mercado.

Una de las limitantes de esta investigación es la falta información actualizada sobre la esperanza de vida de estos negocios, ya que sin ello se dificulta determinar el impacto que ha tenido la inclusión financiera en las Mipymes y su supervivencia.
Por lo tanto, tomando en cuenta la línea de tiempo del anterior censo económico con el próximo inmediato, se invita a realizar futuras investigaciones con dicha premisa para profundizar en la relación entre las dos variables objeto de estudio.

\section{Referencias}

Álvarez, J., León , C., Arias, P., y Londoño, D. (2019). Financiamiento de las MiPymes en Colombia. Bogotá: Banca de las Oportunidades.

Ángeles, X. (2014). Estrategia del uso de las Tic's que permita a las PYMES mejorar su competitividad (Tesis de maestría, Instituto Politécnico Nacional, México D.F.). Recuperado de https://tesis.ipn.mx/handle/123456789/15851

Arellano, P., \& Jimenez, E. (2016). Brechas regionales y sectoriales de las pymes en Chile. Santiago de Chile: Ministerio de Economía, Fomento y Turismo.

Árevalo, J., \& Sosa , J. (2015). Análisis de Competitividad como herramienta para la gerencia global en las micro, pequeñas y medianas empresas (MIPYME). Revista Cientifica, 9(2), 89-96.

Azofeifa, A. (2019). Evolución de la banca en Costa Rica: Una breve descripción de sus orígenes hasta la actualidad. Revista Nacional De Administración, 10(1), 7-28. Recuperado de https://doi.org/10.22458/rna.v10i1.2466

Banco de Mexico. (2017). Indicadores Básicos de Créditos a las Pequeñas y Medianas Empresas (PYMES). Recuperado de http://www.banxico.org.mx/publicaciones-yprensa/rib-creditos-a-pymes/\%7B6F30DAE4E446-DE94-8A66-84CB2E2E0F54\%7D.pdf

Banco Mundial. (2018). Inclusión Financiera. Obtenido de https://www.bancomundial.org/es/topic/financi alinclusion/overview

Bermudez, N. \& Bravo, A. (2019). Modelo Predictivo de los Determinantes del Cierre Empresarial de las MIPYMES en el Ecuador Período 2007-2016, X-Pendientes Económicos, 3(5), 78-93. Recuperado de https://ojs.supercias.gob.ec > Xpedientes_Economicos $>$ article $>$ download

JIMÉNEZ-RICO, Artemio, LAGUNA-CÓRDOBA, Perla Cristina y GUTIÉRREZ-RANGEL, Héctor Fabián. Inclusión financiera: Factor clave en la esperanza de vida de las Mipymes en países de Latinoamérica. Revista de Desarrollo Económico. 2019 
Castillo, V., Figal, L., Maffioli, A., y Ohaco, M. (2016). Asistencias técnicas y competitividad de las MiPyMes. Argentina: Banco Interamericano de Desarrollo.

Chirino, A. (2007). Las MIPYMES en Latinoamérica Estudios e Investigaciones en la Organización. México: Organización Latinoamericana de Administración.

Comisión Nacional Bancaria y de Valores. (2017). Reporte Nacional de Inclusión Financiera . Recuperado de https://www.gob.mx/cnbv/prensa/46-2017reporte-nacional-de-inclusion-financiera8 ?idiom $=\mathrm{es}$

CONDUSEF. (2015). Pymes. Recuperado de https://www.condusef.gob.mx/Revista/index.ph p/usuario-inteligente/educacion-financiera/492pymes

Confecámaras. (2016). Red de Cámaras de Comercio. Recuperado de http://www.confecamaras.org.co/

Correa, J., Ramirez, L., y Castaño, C. (2009). Modelo de gestión financiera integral para MIPYMES en Colombia. Contaduría Universidad de Antioquia (55), 187-201.

DANE. (2016). Departamento Administrativo Nacional de Estadística. Recuperado de https://www.dane.gov.co/index.php/estadisticas -por-tema/comercio-

interno/microestablecimientos

Dini, M., \& Stumpo, G. (2018). Mipymes en América Latina: un frágil desempeño y nuevos desafios para las políticas de fomento (Documentos de Proyectos LC/TS.2019/20). Santiago de Chile, Chile: CEPAL.

Diario Oficial de la Federación, DOF. (2009). Acuerdo por el que se establece la estratificación de las micro, pequeñas y medianas empresas. Recuperado de http://dof.gob.mx/nota_detalle.php?codigo=509 $6849 \&$ fecha $=30 / 06 / 2009$

Ferraz, J., \& Ramos, L. (2018). Inclusión Financiera para la inserción productiva de las empresas de menor tamaño en América Latina. Santiago: CEPAL.
Gallo, J. (2019). Factores que explican la diferencia entre el rendimiento de las instituciones micro financieras y el de los bancos (Tesis de maestría, ESAN Graduate School of Business, Lima, Perú). Recuperado de http://repositorio.esan.edu.pe/bitstream/handle/ ESAN/1636/2019_MAICA_16-1_05-

T.pdf? sequence $=1 \&$ isAllowed $=\mathrm{y}$

INEGI. (2014). Censos Económicos 2014. Recuperado de www.inegi.org.mx

INEGI. (2016). Estadísticas detalladas sobre las micro, pequeñas y medianas empresas el país (BOLETÍN DE PRENSA NÚM. 285/16). Aguascalientes: INEGI.

INEGI. (2016). Encuesta Nacional sobre Productividad y Competitividad de las Micro, Pequeñas y Medianas Empresas (ENAPROCE) 2015. Recuperado de http://www.inegi.org.mx/est/contenidos/proyect os/encuestas/establecimientos/otras/enaproce/de fault

Klynveld Peat Marwick Goerdele, KPMG. (2016). Empresas familiares en México: el desafío de crecer, madurar y permanecer. Recuperado

de https://assets.kpmg.com/content/dam/kpmg/mx/ pdf/2016/12/Empresas\%20Familiares\%20en\%2 0M\%C3\%A9xico\%20el\%20desaf\%C3\%ADo\% $20 \mathrm{de} \% 20$ crecer $\% 20$ madurar $\% 20 \mathrm{y} \% 20$ permane cer.pdf

Kulfas, M. (2018). Banca de desarrollo e inclusión financiera de las pequeñas y medianas empresas. Santiago: CEPAL.

Larios, E. (2016). La Gestión de la Competitividad en la MIPYME Mexicana: Diagnóstico Empírico desde la gestión del conocimiento. Revista de Administração da Unimep, 14(2), 177-209. Recuperado de www.redalyc.org/articulo.oa?id=273746863008 $\mathrm{c}$

Lecuona, R., \& Pavón, L. (2018).. La inclusión financiera de las micro, pequeñas y medianas empresas (mipymes): El caso de México. Recuperado de: https://www.anahuac.mx/mexico/investigacion/ sites/default/files/inline-

files/ECONOM\%C3\%8DA\%20Y\%20NEGOCI OS.\%20Inclusi\%C3\%B3n\%20financiera.pdf 
Martinez, C. (2015). Crecimiento económico y MIPYMES (Tesis presentada como requisito parcial para obtener el grado de Maestría en Economía con Especialidad en Economía Industrial). Facultad de Economía Universidad Autónoma de Nuevo León, México.

Mejía, D. (2018). Inclusión Financiera de MiPymes. Seminario-Taller sobre inclusión financiera de las micro, pequeñas y medianas empresas en América Latina y el Caribe llevado a cabo en Antigua, Guatemala.

Ministerio de Economia, Fomento y Turismo. (2019). Quinta encuesta longitudinal de empresas (ELE5). Recuperado de https:/www.economia.gob.cl/2019/03/12/quint a-encuesta-longitudinal-de-empresas-ele5.htm

Molina, R., López, A., y Schimtt, C. (2016). Factores que influyen en los problemas del emprendimiento de las MIPYMES: una percepción de los expertos. Revista Internacional Administración \& Finanzas, 9(1), 95-113.

Monsalves, J. (2014). La empresa familiar en Chile y el impacto de la cultura latina. Santiago de Chile: Tharawat Magazine.

Mora, E., Vera, M., y Melgarejo, Z. (2015). Planificación estratégica y niveles de competitivdad de las Mipymes del sector comercio en Bogotá. Estudios Gerenciales, 31, 79-87.

Moreno, A., Cuevas, E., y Michi, S. (2015). Determinantes de la supervivencia empresarial en la industria alimentaria de México. Trayectorias(41), 3-28.

Naranjo, J. (2013). La importancia de la cultura empresarial en el desarrollo de la excelencia en servicio. Universidad Militar Nueva Granada, Bogota, Colombia. Recuperado de: https://repository.unimilitar.edu.co/bitstream/ha ndle/10654/11183/NaranjoCallejasJoseFernand o2013.pdf;jsessionid $=88 \mathrm{CE} 5 \mathrm{CF} 8 \mathrm{C} 5 \mathrm{~A} 49269 \mathrm{~A} 0$ 298C935324396C? sequence $=1$

Nielsen Company, \& Visa. (2012). Perspectiva de las Pymes en America Latina. Manuscrito inédito. Recuperado de http://bligoo.com/media/users/0/45940/files/VI SA_Presentacion.pdf
Olivera, I. (2014). El rol de las PyMEs en nuestro país es clave: aportan $40 \%$ del PBI. Obtenido de https://chequeado.com/ultimasnoticias/binner-el-rol-de-las-pymes-en-nuestropais-es-clave-aportan-40-del-pbi/

Ortiz, M. (2019) Factores que inciden en el acceso al financiamiento de las PYMES de la ciudad de Guayaquil (Tesis de maestría, Universidad Católica de Santiago de Guayaquil, Guayaquil, Ecuador). Recuperado de repositorio.ucsg.edu.ec > bitstream > T-UCSGPOS-MAE-226

Pérez, E., \& Titelman, D. (2018). La inclusión financiera para la inserción productiva y el papel de la banca de desarrollo. Santiago, Chile: CEPAL.

Rojas, J. (2015). Financiamiento público y privado para el sector PyME en Argentina (Tesis de posgrado inédita). Universidad de Buenos Aires, Argentina.

Saavedra, M., Tapia, B., y Aguilar, M. (2013). El impacto de las políticas públicas en la MIPYME mexicana. Ciencias Administrativas, (1), 1-19.

Saavedra, M., \& León, E. (2014). Alternativas de financiamiento para la MIPyME Latinoamericana. Panamá: Asociación Latinoamericana de Facultades y Escuelas de Contaduría y Administración.

Servicio de Impuestos Internos. (2015). Estadísticas de empresas por tamaño según ventas . Recuperado de http://www.sii.cl/estadisticas/empresas_tamano _ventas.htm

Stumpo, G. (2013). Micreoempresas y pymes en América Latina. Obtenido de https://slideplayer.es/slide/6122301/

Valdés, R. (2014). El financiamiento de los micronegocios en México . (Tesis de maestría en economía, Universidad Autonóma de Nuevo León, México).

Vite, E. L., \& García, M. L. (2015). Alternativas de financiamiento para la Micro, Pequeña y Mediana Empresa Latinoamericana. Revista Universitaria. Obtenido de http://revistas.userena.cl/index.php/ruta/article/ view/497/624 